\title{
基于涡激抑制的深水钻井隔水管系统 浮力块配置智能优化 ${ }^{*}$
}

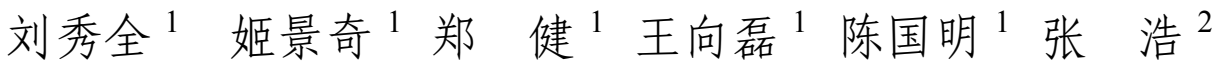 \\ (1. 中国石油大学海洋油气装备与安全技术研究中心 青岛 266580; \\ 2. 中国船舶科学研究中心 无锡 214082)
}

\begin{abstract}
摘要: 浴激疲劳是深水钻井隔水管系统的主要失效模式之一, 如何通过隔水管系统浮力块配置减小隔水管系统浴激疲劳损伤 是要解决的关键问题, 采用基因编码方式表征隔水管系统浮力块配置, 融合遗传算法和隔水管系统浴激疲劳分析模型提出深 水钻井隔水管系统浮力块配置智能优化方法, 开发深水钻井隔水管系统浮力块配置智能优化系统, 开展不同水深下的深水钻 井隔水管系统浮力块配置优化设计, 并采用枚举法对隔水管系统浮力块配置智能优化方法进行验证分析。结果表明, 提出的 隔水管系统浮力块配置智能优化方法可以精确高效地开展隔水管系统浮力块配置优化设计, 与传统的隔水管系统配置经验设 计相比，提出的隔水管系统浮力块配置优化方法可以大大改善隔水管系统浴激疲劳性能。
\end{abstract}

关键词: 深水; 钻井隔水管; 浴激疲劳; 遗传算法; 智能优化

中图分类号: TE52

\section{Intelligent Optimization of Buoyancy Configuration for Deepwater Drilling Riser System Based on Vortex-induced Vibration Suppression}

LIU Xiuquan $^{1} \quad$ JI Jingqi $^{1} \quad$ ZHENG Jian $^{1} \quad$ WANG Xianglei $^{1} \quad$ CHEN Guoming $^{1}$ ZHANG Hao ${ }^{2}$

(1. Centre for Offshore Engineering and Safety Technology, China University of Petroleum, Qingdao 266580;

2. China Ship Scientific Research Center, Wuxi 214082)

\begin{abstract}
Vortex-induced fatigue is one of the main failure modes of the deepwater drilling riser system, and how to reduce the vortex-induced fatigue damage of the riser system through the buoyancy configuration design is the key problem to be solved. An intelligent optimization method of buoyancy configuration for deepwater drilling riser system is proposed based on genetic algorithm and VIV analysis model of riser system with buoyancy configuration characterized by the gene coding method. The intelligent optimization system of buoyancy configuration for deepwater drilling riser system is developed and enumeration method is applied for verification. At last, buoyancy configuration optimization design for different water depth is carried out. The results show that the proposed method can optimize the vortex-induced fatigue design of the riser system accurately and efficiently. Compared with the traditional experience design of the riser system, the proposed optimization method of buoyancy configuration can greatly improve the vortex-induced fatigue performance of the riser system.
\end{abstract}

Key words: deepwater; drilling riser; vortex-induced fatigue; genetic algorithm; intelligent optimization

\section{0 前言}

深水钻井隔水管系统是连接海底井口和海面钻 井平台的关键装备, 其长期处于海洋自然环境中,

* 国家自然科学基金(51809279)、国家重点基础研究发展计划(973 计划, 2015CB251203)、教育部长江学者和创新团队发展计划(IRT14R58)、国 家自然科学基金(51239008)、山东省自然科学基金联合专项 (ZR2014EL018)和中央高校基本科研业务费专项资金(17CX02025A)资 助项目。20170812 收到初稿, 20180106 收到修改稿
当海水流经隔水管时其两侧会产生交替的漩浴释 放，漩浴释放激励隔水管系统振动，当漩浴释放频 率接近隔水管横向振动固有频率时, 隔水管会发生 明显的涡激振动现象, 浴激振动会引起隔水管系统 浴激疲劳损伤甚至断裂 ${ }^{[1-4]}$ 。因此, 隔水管系统浴激 疲劳一直是国内外学者研究的热点与难点。目前已 形成多种隔水管浴激疲劳分析方法, 主要包括浴激 振动试验、流体动力学仿真和半经验模型 ${ }^{[5-8]}$ 。在隔 水管系统浴激疲劳分析方法的基础上，如何减小浴 
激疲劳损伤是隔水管系统设计的关键问题, 通过有 效的隔水管系统浴激疲劳抑制设计减小隔水管系统 涡激疲劳损伤, 提高隔水管系统疲劳性能, 对保障 深水钻井隔水管系统作业安全具有重要意义。

目前, 国内外在深水钻井隔水管系统浴激疲劳 抑制方面开展了大量的研究工作。通过安装螺旋列 板、减振器等浴激抑制装置扰乱漩浴释放以达到浴 激抑制的目的, 但安装与拆卸涡激抑制装置将使隔 水管的下放与回收作业复杂化, 导致作业时间延长, 尤其是深水钻井隔水管系统需要频繁地下放与回收 作业, 从而限制浴激抑制装置在钻井隔水管上的应 用, 目前钻井隔水管系统基本不使用隔水管浴激抑 制装置 ${ }^{[9]}$ 。本文旨在从隔水管系统本身浮力块配置 的角度去解决问题, 通过合理的浮力块配置来达到 隔水管涡激抑制的目的。目前, 孙友义等 ${ }^{[10]}$ 研究浮 力块配置对隔水管系统涡激疲劳损伤的影响, 开展 浮力块覆盖率在 $0 \% 、 25 \% 、 50 \%$ 和 $100 \%$ 下的隔水 管系统浴激疲劳损伤分析, 确定较好的隔水管系统 浮力块配置方案。但只用几种典型的浮力块配置代 表所有的浮力块配置方案有明显局限性, 以 $1000 \mathrm{~m}$ 深水钻井隔水管系统为例, 每个隔水管单根的长度 为 $18.288 \mathrm{~m}$, 整个隔水管系统约由 54 个隔水管单根 组成, 每个单根均存在有浮力块和无浮力块两种可 能性, 则 $1000 \mathrm{~m}$ 的深水钻井隔水管系统浮力块配 置方案共有 $2^{54}\left(1.8 \times 10^{16}\right)$ 种, 相对所有的浮力块配置 方案而言, 几种典型的浮力块配置方案局限性非常 明显 ${ }^{[10-14]}$ 。因此, 如何在庞大的浮力块配置方案中 优选出浴激疲劳性能较好的配置方案, 是拟解决的 关键科学难题。

在已有研究成果的基础上, 针对基于涡激抑制 的隔水管系统浮力块配置方案优化设计难题, 采用 基因编码方式表征隔水管系统浮力块配置, 引入遗 传算法提出基于浴激抑制的深水钻井隔水管系统浮 力块配置智能优化方法, 开发深水钻井隔水管系统 浮力块配置智能优化系统, 确定不同水深下的隔水 管系统浮力块配置方案, 为我国南海深水钻井隔水 管系统浮力块配置提供参考。

\section{1 浴激疲劳分析模型}

深水钻井隔水管系统浴激疲劳损伤分析较为复 杂, 麻省理工大学在大量试验数据的基础上, 开发 了隔水管系统涡激疲劳专业分析软件 SHEAR7, 已 在国际上得到广泛认可与应用 ${ }^{[15-16]}$, 本文也选用 SHEAR7 的求解算法, 以确保优化结果的可靠性。 此软件基于能量平衡原理预测隔水管系统的各阶模
态响应, 并采用模态叠加法计算隔水管系统总体响 应, 对于任意第 $r$ 阶模态的隔水管系统浴激振动控 制方程为 ${ }^{[15]}$

$$
M_{r} \ddot{q}_{r}(t)+R_{r} \dot{q}_{r}(t)+K_{r} q_{r}(t)=P_{r}(t)
$$

式中, $M_{r}$ 为模态质量, $R_{r}$ 为模态阻尼, $K_{r}$ 为模态刚 度, $P_{r}$ 为模态力, $q_{r}$ 为模态位移。

首先, 需要根据斯托哈斯数与流剖面计算漩浴 释放频带范围, 相应的隔水管系统涡激振动模态应 在浴激振动载荷激励频率范围内, 可初步篎选出可 能会参与涡激振动的各阶模态, 最小与最大漩浴释 放频率可表示为

$$
\left\{\begin{array}{l}
f_{\min }=\frac{S_{\mathrm{t}} u_{\min }}{d_{\mathrm{h}}} \\
f_{\max }=\frac{S_{\mathrm{t}} u_{\max }}{d_{\mathrm{h}}}
\end{array}\right.
$$

式中, $S_{\mathrm{t}}$ 为斯托哈斯数, $u_{\min }$ 和 $u_{\max }$ 分别为流剖面 的最小与最大流速， $d_{\mathrm{h}}$ 为隔水管水动力外径。

对于符合激励频率范围内的各阶隔水管模态, 分别基于能量平衡原理计算各阶模态振幅, 一个周 期内 $r$ 阶模态的平均模态输入能量可表示为

$$
\Pi_{r}^{\mathrm{i}}=\frac{1}{4} \int_{L_{r}} \rho d_{\mathrm{h}} u^{2}(z) C_{\mathrm{L}}\left(z ; \omega_{r}\right) A_{r} \omega_{r}\left|Y_{r}(z)\right| \mathrm{d} z
$$

式中, $\rho$ 为海水密度, $u$ 为海流流速, $C_{\mathrm{L}}$ 为升力系 数, $z$ 为水深, $A_{r}$ 为 $r$ 阶模态位移幅值, $w_{r}$ 为 $r$ 阶固 有频率, $Y_{r}$ 为 $r$ 阶模态振型, $L_{r}$ 为 $r$ 阶模态的能量 输入区长度。

一个周期内 $r$ 阶模态的平均模态输出能量为

$$
\begin{aligned}
\Pi_{r}^{\mathrm{o}}= & \frac{1}{2} \int_{L-L_{r}} R_{\mathrm{h}}(z) Y_{r}^{2}(z) A_{r}^{2} \omega_{r}^{2} \mathrm{~d} z+ \\
& \frac{1}{2} \int_{0}^{L} R_{\mathrm{s}}(z) Y_{r}^{2}(z) A_{r}^{2} \omega_{r}^{2} \mathrm{~d} z
\end{aligned}
$$

式中, $R_{\mathrm{h}}$ 为水动力阻尼, $R_{\mathrm{S}}$ 为结构阻尼, $L$ 为隔水 管系统长度。

$r$ 阶模态下, 当 $\Pi_{r}^{\mathrm{i}}=\Pi_{r}^{\mathrm{o}}$ 时, 隔水管系统达到 涡激振动稳定，则 $r$ 阶模态下隔水管系统的无因次 振幅为

$$
\frac{A_{r}}{d_{\mathrm{h}}}=\frac{\frac{1}{2} \int_{L_{r}} \rho u^{2}(z) C_{\mathrm{L}}\left(z ; \omega_{r}\right)\left|Y_{r}(z)\right| \mathrm{d} z}{\int_{L-L_{r}} R_{\mathrm{h}}(z) Y_{r}^{2}(z) \omega_{r} \mathrm{~d} z+\int_{0}^{L} R_{\mathrm{s}}(z) Y_{r}^{2}(z) \omega_{r} \mathrm{~d} z}
$$

基于式(5)开展不同模态阶次下的隔水管系统 涡激振动迭代计算, 确定各阶模态振幅, 其模态方 均根位移可表示为 


$$
y(z)=\left\{\sum_{r} \frac{1}{2}\left|\sum_{n} Y_{n}(z) P_{n r} H_{n r}\left(\frac{\omega_{r}}{\omega_{n}}\right)\right|^{2}\right\}^{\frac{1}{2}}
$$

式中, $H_{n r}$ 为频率响应函数。

方均根应力可表示为

$$
S(z)=\left\{\sum_{r} \frac{1}{8}\left|\sum_{n} Y_{n}^{\prime \prime}(z) E d_{\mathrm{s}} P_{n r} H_{n r}\left(\frac{\omega_{r}}{\omega_{n}}\right)\right|^{2}\right\}^{\frac{1}{2}}
$$

式中, $Y_{n}^{\prime \prime}(z)$ 为模态曲率, $E$ 为弹性模量, $d_{\mathrm{s}}$ 为隔 水管强度外径。

第 $r$ 阶模态响应造成的隔水管浴激疲劳损伤根 据瑞利公式计算

$$
D_{r}(z)=\frac{w_{r} T}{2 \pi C}\left(2 \sqrt{2} k S_{r}(z)\right)^{b} \Gamma\left(\frac{b+2}{2}\right)
$$

式中, $T$ 为服役时间, $k$ 为应力集中系数, $C$ 和 $b$ 为 隔水管疲劳 $S-N$ 曲线中的常数, $\Gamma$ 为伽马函数。

隔水管系统在任意 $z$ 处的总疲劳损伤为各阶模 态疲劳损伤之和, 可表示为

$$
D(z)=\sum D_{r}(z)
$$

\section{2 浮力块配置智能优化方法}

深水钻井隔水管系统长期处于海洋环境中, 受 到不同海流流速的影响, 其涡激疲劳损伤是在不同 海洋环境下逐渐累积的过程, 隔水管系统浮力块配 置优化的目标即为减小隔水管系统长期浴激疲劳损 伤。为此, 在开展隔水管系统浮力块配置优化之前, 需要建立海洋流速的长期分布模型, 以提高基于浴 激抑制的隔水管系统配置优化结果的适用性和通用 性, 考虑海流流速的长期统计特征满足威布尔分布, 可建立不同超越概率下的海流流速，可表示为 ${ }^{[17]}$

$$
P=1-F(u)=\exp \left(-\left(\frac{u}{\theta}\right)^{\beta}\right)
$$

式中, $P$ 为超越概率, $\beta$ 和 $\theta$ 分别为海流流速威布 尔分布的形状参数和尺度参数。

随着超越概率的增大海流流速逐渐减小，不同 超越概率下的海流工况发生概率为

$$
p_{i}= \begin{cases}1-P_{1} & i=1 \\ P_{i}-P_{i-1} & i>1\end{cases}
$$

在深水钻井隔水管系统浴激疲劳分析模型和长 期海洋环境的基础上, 以减小隔水管系统最大浴激 疲劳损伤为目标, 建立基于浴激抑制的隔水管系统 浮力块配置优化数学模型, 可表示为

$$
\min _{\boldsymbol{R}} D(\boldsymbol{R})=\sum_{i=1}^{N} p_{i} D_{i}(\boldsymbol{R})
$$

式中, $\boldsymbol{R}$ 为隔水管系统浮力块配置方案集合, $N$ 为 海况总数, $p_{i}$ 为第 $i$ 个海况的发生概率, $D_{i}$ 为第 $i$ 个海况下的隔水管系统最大浴激疲劳损伤。

隔水管浮力块配置优化数学模型中的优化变量 为隔水管系统浮力块配置, 且隔水管系统浮力块配 置方案随着隔水管单根数目的增加呈指数式增大, 如何表征隔水管系统浮力块配置并快速地确定最优 浮力块配置是难点。为此, 借鉴遗传学思想, 采用 基因编码方式表征隔水管系统浮力块配置, 如图 1 所示。基因 1 代表浮力块单根, 基因 0 代表裸单根, 则通过不同基因组合可有效表征不同的隔水管系统 浮力块配置。在此基础上, 借鉴生物进化论思想, 通过自然选择、突变和交叉等作用机制, 遵循 “适 者生存” 的原则, 优选出涡激疲劳损伤较低的浮力 块配置方案。目前, 遗传算法(Genetic algorithm, $\mathrm{GA})$ 是模拟生物在自然环境中的遗传和进化的过程 而形成的自适应全局优化搜索算法, 通过对当前群体 施加选择、交叉、变异等一系列操作，从而产生新一 代群体, 并使群体进化到接近最优解的状态, 从而为 隔水管系统浮力块配置优化提供有效的方法。
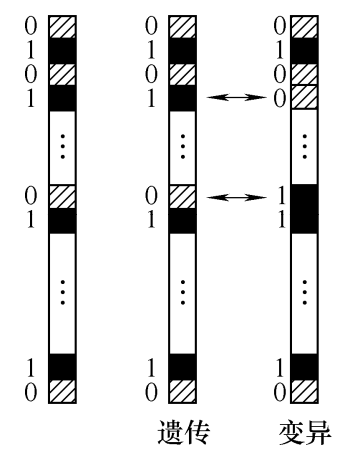

图 1 浮力块配置表征
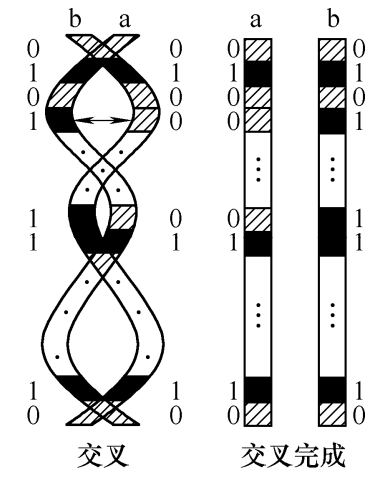

交叉完成
在隔水管系统浴激疲劳分析模型、海流长期分 布模型和遗传算法的基础上，提出基于涡激抑制的 深水钻井隔水管系统浮力块配置智能优化方法及流 程, 如图 2 所示。整个分析流程主要包括浮力块配 置优化主模块、浮力块配置编译模块、海流长期分 布模拟模块和浴激疲劳损伤评估模块, 浮力块配置 优化主模块基于遗传算法开展不同浮力块配置种群 的生成、交叉、变异及选择等; 浮力块配置编译模 块可以将基因代码表征的隔水管系统浮力块配置编 译为实际的隔水管系统浮力块配置; 海流长期分布 模块用于生成不同超越概率下的海流流速及发生概 率。编译后的浮力块配置种群和海流参数传递到浴 激疲劳损伤评估模块, 依次完成不同海流流速和浮 
力块配置下的隔水管系统浴激疲劳损伤评估, 确定 不同浮力块配置下的综合浴激疲劳损伤并反馈至浮 力块配置优化主模块, 进一步优选出浴激疲劳损伤 性能较好的浮力块配置, 依次进行下一轮的浮力块 配置进化, 直至得到最优的浮力块配置方案。通过 各模块的协同运行可以有效开展基于浴激抑制的隔 水管系统浮力块配置优化, 并采用 Matlab 软件开 发隔水管系统浮力块配置优化系统, 实现隔水管系 统浮力块配置的自动智能优化, 为基于浴激抑制的 隔水管系统浮力块配置优化提供一种行之有效的 工具。

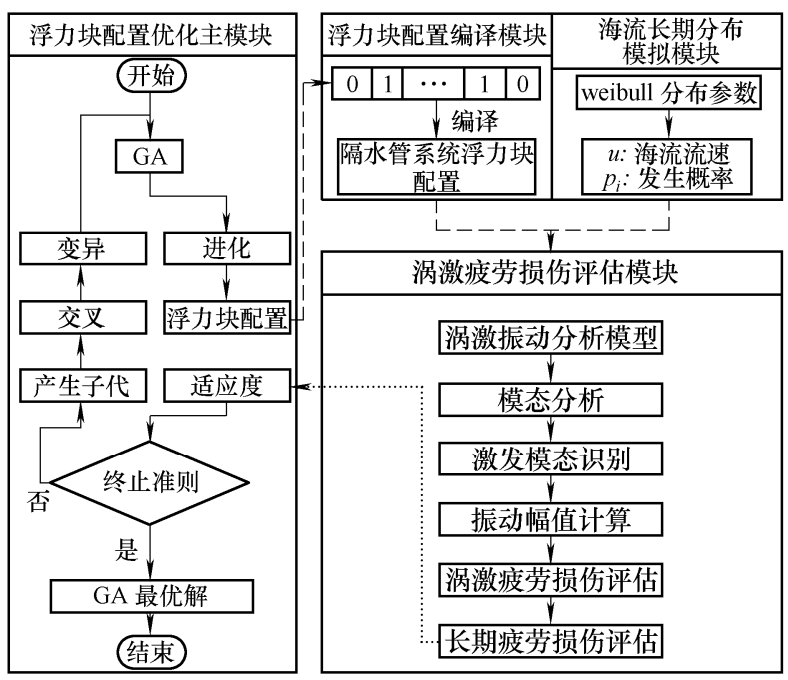

图 2 智能优化流程

\section{3 算例分析}

\section{1 基础数据}

采用基于涡激抑制的深水钻井隔水管系统浮力 块配置智能优化方法, 开展不同水深下的深水钻井 隔水管系统浮力块配置优化及验证研究, 基本参数 见表 1 , 根据表 1 中的基本信息可以建立不同水深

表 1 基本参数

\begin{tabular}{|c|c|}
\hline 参数 & 数值 \\
\hline 隔水管单根长度 $L / \mathrm{m}$ & 18.288 \\
\hline 隔水管单根强度外径 $d_{s} / \mathrm{m}$ & 0.5334 \\
\hline 裸单根水动力外径 $d_{\mathrm{h}} / \mathrm{m}$ & 0.8382 \\
\hline 浮力单根水动力外径 $d_{\mathrm{h}} / \mathrm{m}$ & 1.372 \\
\hline 斯托哈斯数 $S_{\mathrm{t}}$ & 0.22 \\
\hline 海水密度 $\rho /\left(\mathrm{kg} / \mathrm{m}^{3}\right)$ & 1025 \\
\hline 隔水管弹性模量 $E / \mathrm{GPa}$ & 210 \\
\hline \multirow{2}{*}{$S-N$ 曲线常数 $C$} & $2.2 \times 10^{15}$ (应力 $S<74 \mathrm{MPa}$ ) \\
\hline & $4.1 \times 10^{11}$ (应力 $S \geqslant 74 \mathrm{MPa}$ ) \\
\hline \multirow{2}{*}{$S-N$ 曲线常数 $b$} & 5 (应力 $S<74 \mathrm{MPa}$ ) \\
\hline & 3 (应力 $S \geqslant 74 \mathrm{MPa}$ ) \\
\hline 应力集中系数 $k$ & 1.3 \\
\hline
\end{tabular}

和不同单根类型组合下的隔水管系统涡激疲劳分析 模型。

此外, 为了提高隔水管系统浮力块配置优化结 果的通用性, 结合我国南海海洋自然环境, 基于威 布尔分布建立不同超越概率下的海流流剖面, 海流 流剖面如图 3 所示, 不同超越概率下的表面海流流 速见表 2 。

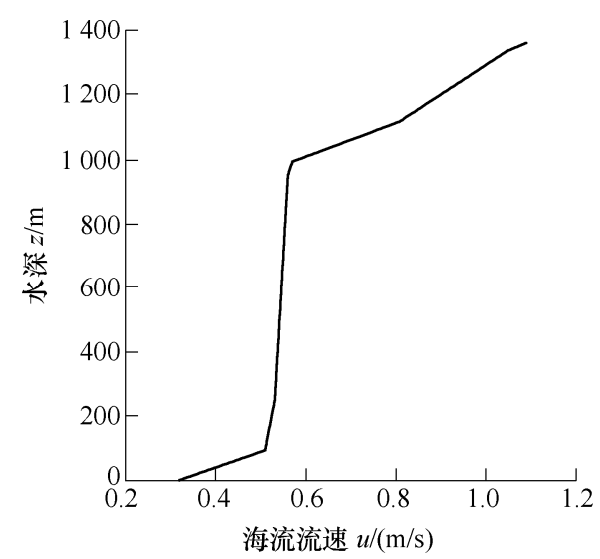

图 3 海流超越流剖面

表 2 不同超越概率下的表面海流流速

\begin{tabular}{cccccc}
\hline 超越概率 $P$ & 0.95 & 0.90 & 0.80 & 0.70 & 0.60 \\
\hline 海流流速 $u /(\mathrm{m} / \mathrm{s})$ & 0.007 & 0.015 & 0.032 & 0.052 & 0.075 \\
\hline \hline 超越概率 $P$ & 0.50 & 0.40 & 0.30 & 0.20 & 0.15 \\
\hline 海流流速 $u /(\mathrm{m} / \mathrm{s})$ & 0.103 & 0.137 & 0.182 & 0.245 & 0.29 \\
\hline \hline 超越概率 $P$ & 0.10 & 0.075 & 0.05 & 0.03 & 0.02 \\
\hline 海流流速 $u /(\mathrm{m} / \mathrm{s})$ & 0.353 & 0.399 & 0.463 & 0.544 & 0.609 \\
\hline \hline 超越概率 $P$ & 0.01 & 0.0075 & 0.005 & 0.0025 & 0.001 \\
\hline 海流流速 $u /(\mathrm{m} / \mathrm{s})$ & 0.72 & 0.766 & 0.831 & 0.943 & 1.091 \\
\hline
\end{tabular}

\section{2 优化及验证}

首先以由 8 个隔水管单根组成的钻井隔水管系 统为例, 开展基于浴激抑制的钻井隔水管系统浮力 块配置智能优化, 优化过程中采用开发的隔水管系 统浮力块配置优化系统自动生成隔水管系统浮力块 配置初始种群, 以减小隔水管系统最大浴激疲劳损 伤为目标, 依次完成不同隔水管系统浮力块配置种 群的进化, 隔水管系统配置进化过程及涡激疲劳损 伤如图 4 所示, 图中黑色区域代表浮力块单根, 白 色区域代表裸单根。

由图 4a 可知, 隔水管系统浮力块配置进化过程 中, 前期的浮力块配置方案波动性较大, 每个位置 处的隔水管单根类型基本上都发生波动, 通过前期 浮力块配置方案的大幅波动可以确保最终的优化方 案为全局最优结果。随着隔水管系统浮力块配置进 化过程的推移, 隔水管系统浮力块配置波动性逐渐 减小, 最终通过一系列的迭代搜索确定最优的隔水 管系统浮力块配置。由图 $4 \mathrm{~b}$ 可知, 初始阶段随机生 
成的隔水管系统浮力块配置对应的涡激疲劳损伤较 大; 在进化前期阶段, 受隔水管系统浮力块配置大 幅波动的影响, 进化前期阶段的隔水管系统浴激疲 劳损伤大幅下降; 随着进化过程的深入, 隔水管系 统浮力块配置变化较小, 相应的隔水管系统涡激疲 劳损伤也逐渐趋于最优值; 当隔水管系统的涡激疲 劳损伤变化幅值满足 GA 终止准则时, 隔水管系统 浮力块配置进化过程完成, 从而确定最优的隔水管 系统浮力块配置方案。

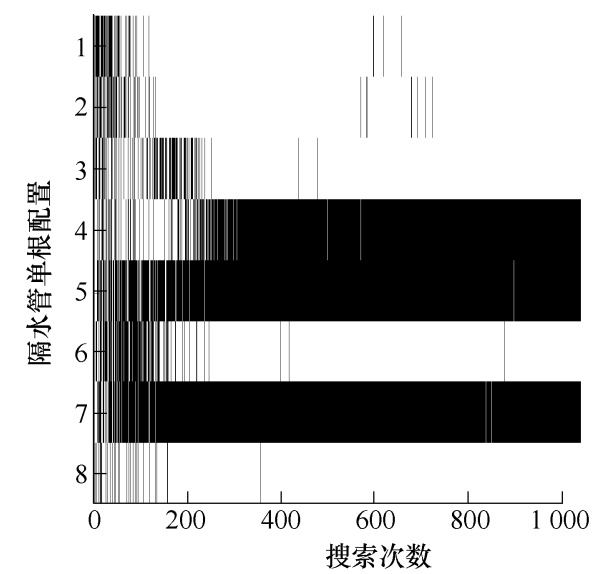

(a) 浮力块配置进化过程

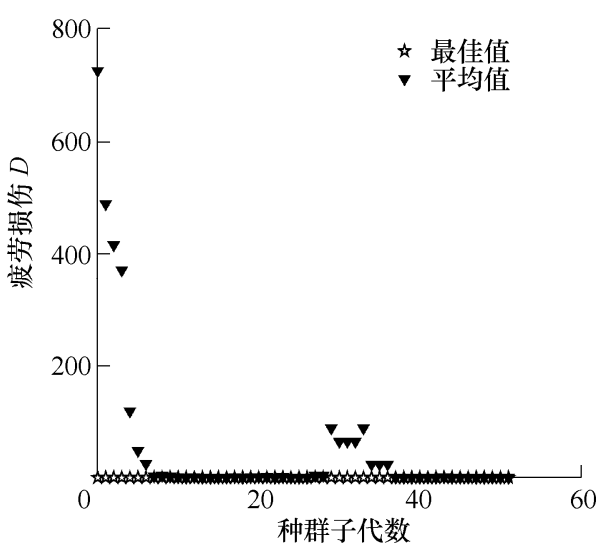

(b) 浴激痕劳损伤

图 4 浮力块配置进化过程

为了验证基于 GA 的隔水管系统浴激疲劳优化 结果的准确性, 采用枚举法(Enumeration algorithm, EA)对隔水管系统浮力块配置优化方法进行验证。 依次开展不同隔水管系统长度下的浴激疲劳损伤验 证, 隔水管系统分别由 $8 、 10 、 12 、 14$ 个隔水管单 根组成, 则对应的浮力块配置方案数量分别为 $256\left(2^{8}\right) 、 1024\left(2^{10}\right) 、 4096\left(2^{12}\right) 、 16384\left(2^{14}\right)$ 。采用 枚举法计算所有隔水管系统浮力块配置方案下的浴 激疲劳损伤, 选取浴激疲劳损伤最小值下的浮力块 配置作为最优方案, 并将计算结果与 GA 优化结果 进行对比, 见表 3。其中, GA 优化率为 GA 优化结 果在 EA 所有结果中从大至小的排序除以 EA 所有
结果数目, 优化率越高说明 $\mathrm{GA}$ 得到的结果越接近 最优值。结果表明, 隔水管系统的 GA 优化和 EA 优化结果基本一致, 隔水管系统浮力块配置优化方 法具备较高的精度, 可以满足基于浴激抑制的隔水 管系统浮力块配置优化的精度要求。

表 3 优化精度对比

\begin{tabular}{cccc}
\hline 隔水管系统单根数 & GA 疲劳损伤 & EA 疲劳损伤 & GA 优化率 $(\%)$ \\
\hline 8 & $9.04 \times 10^{-6}$ & $1.89 \times 10^{-6}$ & 97.66 \\
10 & $1.03 \times 10^{-10}$ & $1.03 \times 10^{-10}$ & 100 \\
12 & $1.21 \times 10^{-13}$ & $1.71 \times 10^{-16}$ & 99.51 \\
14 & $1.09 \times 10^{-11}$ & $1.68 \times 10^{-15}$ & 99.85 \\
\hline
\end{tabular}

上述分析表明，通过 EA 也可以完成基于浴激 抑制的隔水管系统浮力块配置优化，但随着隔水管 系统长度增大, $\mathrm{EA}$ 的计算量呈指数式增长, 影响 隔水管系统浮力块配置优化效率。为此, 提取不同 隔水管系统长度下的浮力块配置优化所需时间，见 表 4。其中, 优化过程中使用的计算机配置为 Intel Core i5-6600 CPU@3.30 GHz。

表 4 优化效率对比

\begin{tabular}{cccc}
\hline 序号 & 隔水管系统单根数 & $\mathrm{GA}$ 耗时 $/ \mathrm{s}$ & $\mathrm{EA}$ 耗时 $/ \mathrm{s}$ \\
\hline 1 & 8 & 126 & 30 \\
2 & 10 & 130 & 118 \\
3 & 12 & 133 & 490 \\
4 & 14 & 141 & 2088 \\
\hline
\end{tabular}

由表 4 可知, 当隔水管系统长度较小时, GA 所需的时间较长, 主要是由于 $\mathrm{GA}$ 迭代搜索过程中 严格的终止准则导致, 但当隔水管系统长度较大时, EA 所需的时间呈指数式增大, 当隔水管单根数为 14 时, EA 所需的时间远远超过 GA 所需时间。此 外, 根据表 4 统计可知, EA 过程中每个隔水管系 统浮力块配置计算所需时间约为 $0.125 \mathrm{~s}$, 则开展 $1000 \mathrm{~m}$ 隔水管系统浮力块配置优化时, $1000 \mathrm{~m}$ 隔 水管系统由 54 个隔水管单根组成, 共包括 $2^{54}$ 种浮 力块配置方案, 所需计算时间约为 $0.125 \times 2^{54}=$ $2.25 \times 10^{15} \mathrm{~s}\left(2.6 \times 10^{10}\right.$ 天), 即采用 $\mathrm{EA}$ 算法无法开展 深水钻井隔水管系统配置优化，但 GA 算法所需时 间随隔水管系统长度增大变化不明显, 可用于后续 基于浴激抑制的深水钻井隔水管系统浮力块配置 优化。

\section{3 深水钻井隔水管浮力块配置优化}

基于浮力块配置智能优化方法依次开展 500 $\mathrm{m} 、 800 \mathrm{~m} 、 1100 \mathrm{~m}$ 和 $1400 \mathrm{~m}$ 水深下的隔水管系 统浮力块配置优化, 浮力块配置进化过程中隔水管 系统的涡激疲劳损伤如图 5 所示。结果表明, 浮力 块配置智能优化方法可有效开展基于浴激抑制的隔 
水管系统浮力块配置优化, 通过隔水管系统浮力块 配置优化可大大减小隔水管系统涡激疲劳损伤, 达 到隔水管系统涡激疲劳损伤抑制的目的。优化后的 隔水管系统浮力块配置如图 6 所示, 图中黑色部分 代表浮力块单根, 白色部分代表裸单根。隔水管系 统的浮力块单根覆盖率约为 $40 \%$, 浮力块单根整体 上基本呈间断式分布。

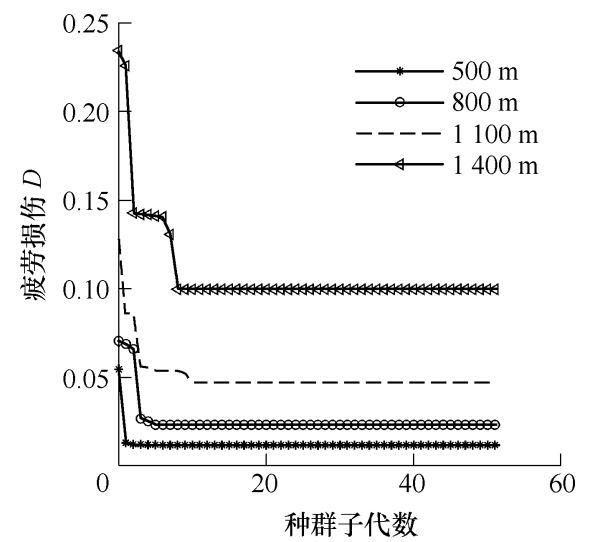

图 5 不同隔水管长度下浴激疲劳优化过程

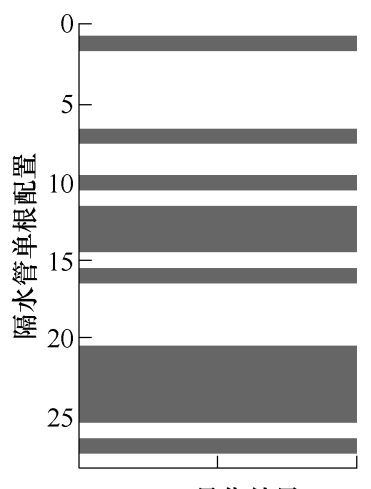

GA 最优结果

(a) $500 \mathrm{~m}$ ( 单根数 28)

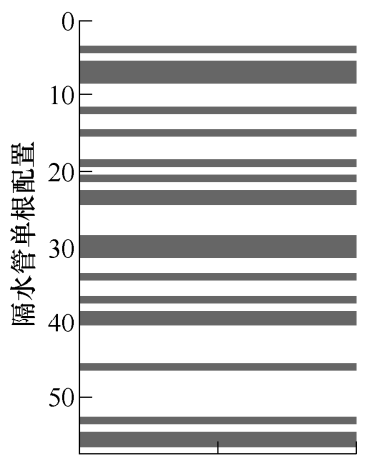

GA 最终结果

(c) $1100 \mathrm{~m}$ ( 单根数 60)

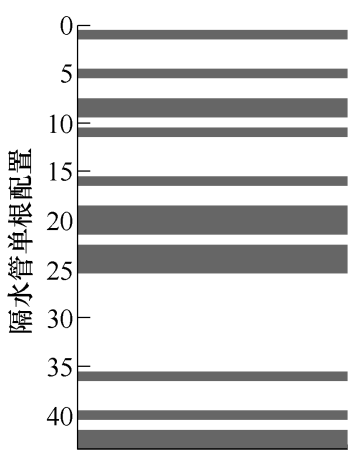

GA 最优结果

(b) $800 \mathrm{~m}$ ( 单根数 43)

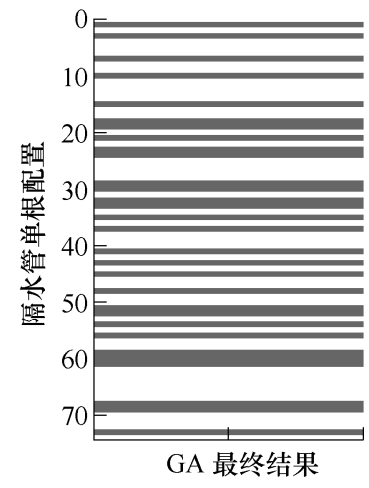

(d) $1400 \mathrm{~m}$ ( 单根数 76)
图 6 不同隔水管长度下的浮力块配置

传统的隔水管系统浮力块配置优化方案采用浮 力块单根和裸单根均匀交错分布形式 ${ }^{[10]}$, 将基于浴 激抑制的隔水管系统浮力块配置优化结果与传统的 隔水管系统浮力块配置优化方案进行对比, 见表 5 。 结果表明, 相比传统的隔水管系统浮力块配置方案,
隔水管系统浮力块配置智能优化方法可以大幅减小 隔水管系统涡激疲劳损伤, 提高隔水管系统安全服 役水平, 从而为我国深水钻井隔水管系统浮力块配 置优化提供一种行之有效的方法。

表 5 不同设计方法对比

\begin{tabular}{|c|c|c|c|c|c|}
\hline \multirow[b]{2}{*}{ 序号 } & \multirow[b]{2}{*}{$\begin{array}{l}\text { 水深 } \\
/ \mathrm{m}\end{array}$} & \multicolumn{2}{|c|}{ 传统法疲劳损伤 } & \multirow{2}{*}{$\begin{array}{c}\text { GA 法 } \\
\text { 疲劳损伤 }\end{array}$} & \multirow{2}{*}{$\begin{array}{c}\text { 相对 } \\
\text { 降低值(\% }\end{array}$} \\
\hline & & $\begin{array}{c}\text { 25\%浮力块 } \\
\text { 覆盖率 }\end{array}$ & $\begin{array}{c}50 \% \text { 浮力块 } \\
\text { 覆盖率 }\end{array}$ & & \\
\hline 1 & 500 & 0.0232 & 0.0119 & 0.0118 & 0.84 \\
\hline 2 & 800 & 0.0824 & 0.6753 & 0.0232 & 71.844 \\
\hline 3 & 1100 & 0.0771 & 0.3271 & 0.0442 & 42.616 \\
\hline 4 & 1400 & 0.1124 & 2.237 & 0.0927 & 17.573 \\
\hline
\end{tabular}

此外, 深水钻井隔水管系统由一系列的隔水管裸 单根和浮力块单根组成, 其中浮力块单根的湿重较 小, 为了减小隔水管系统顶部张紧力, 工程上常要求 隔水管系统浮力块单根达到一定的最低覆盖率, 并为 隔水管系统浮力块配置优化设定不等式约束条件。为 此, 进一步研究最低浮力块覆盖率对隔水管系统浴激 疲劳损伤的影响, 分别开展浮力块覆盖率大于 $50 \%$ 和 70\%约束条件下的隔水管系统浴激疲劳损伤优化 分析, 见表 6。结果表明, 增加最低浮力块覆盖率优 化约束条件后, 隔水管系统涡激疲劳损伤会增大, 且随着要求的最低浮力块覆盖率增大, 可以选择的 浮力块覆盖率范围变小, 隔水管系统浮力块配置优 化的约束条件更严格, 相应的隔水管系统疲劳损伤 也会增大，但通过隔水管系统浮力块配置智能优化 算法, 在最低浮力块覆盖率约束条件下可确定涡激 疲劳性能较好的隔水管系统浮力块配置。

表 6 不同最低浮力块覆盖率下的涡激疲劳损伤

\begin{tabular}{ccc}
\hline 水深 $/ \mathrm{m}$ & 浮力块覆盖率大于 $50 \%$ & 浮力块覆盖率大于 $70 \%$ \\
\hline 500 & 0.0278 & 0.0346 \\
800 & 0.0309 & 0.1877 \\
1100 & 0.0533 & 0.3068 \\
1400 & 0.2515 & 0.8270 \\
\hline
\end{tabular}

\section{4 结论}

（1）采用基因编码方式表征隔水管系统浮力块 配置, 融合遗传算法和隔水管系统浴激疲劳分析模 型提出深水钻井隔水管系统浮力块配置智能优化方 法, 开发深水钻井隔水管系统浮力块配置智能优化 系统, 主要包括浮力块配置优化主模块、浮力块配 置编译模块、海流长期分布模拟模块和浴激疲劳损 伤评估模块, 通过各模块的协同运行可以有效开展 基于浴激抑制的隔水管系统浮力块配置智能优化。

(2) 开展钻井隔水管系统浮力块配置智能优化 
设计研究, 并采用枚举法对隔水管系统浮力块配置 智能优化方法进行验证, 结果表明, 隔水管系统浮 力块配置智能优化算法可精确快速地确定最优的浮 力块配置, 通过浮力块配置优化可以明显降低隔水 管系统浴激疲劳损伤。

(3) 开展不同水深下的深水钻井隔水管系统浮 力块配置智能优化设计, 并与传统的浮力块配置设 计方案对比, 结果表明不同水深下的隔水管系统浮 力块配置基本呈间断式分布, 深水钻井隔水管系统 浮力块配置智能优化方法可大幅改善隔水管系统浴 激疲劳性能，提高隔水管系统安全服役水平。

(4) 开展不同最低浮力块覆盖率约束条件下 的隔水管系统涡激疲劳损伤优化分析, 结果表明, 增加最低浮力块覆盖率优化约束条件后, 隔水管 系统浴激疲劳损伤增大, 且要求的最低浮力块覆 盖率越大, 基于浴激抑制的隔水管系统浮力块配 置优化约束条件更严格, 相应的隔水管系统涡激 疲劳损伤越大。

\section{参 考 文 献}

[1] International Organization for Standardization. ISO 13624-1 Petroleum and natural gas industries-Drilling and production equipment-Part 1: Design and operation of marine drilling riser equipment[S]. Geneva : International Organization for Standardization, 2009.

[2] 畅元江, 陈国明, 许亮斌, 等. 超深水钻井隔水管设计 影响因素 [J]. 石油勘探与开发, 2009，36(4): 523-528. CHANG Yuanjiang, CHEN Guoming, XU Liangbin, et al. Influential factors for the design of ultra-deepwater drilling risers $[\mathrm{J}]$. Petroleum Exploration and Development, 2009, 36(4): 523-528.

[3] 李伟, 袁新安, 陈国明, 等. 基于 ACFM 的隔水管表 面裂纹链式阵列检测探头设计与试验研究 $[\mathrm{J}]$. 机械工 程学报, 2017, 53(8): 8-15.

LI Wei, YUAN Xinan, CHEN Guoming, et al. Research on the detection of surface cracks on drilling riser using the chain alternating current field measurement probe array[J]. Journal of Mechanical Engineering, 2017, 53(8): 8-15.

[4] GücüYEN Engin. Numerical analysis of deteriorated sub-sea pipelines under environmental loads[J]. Chinese Journal of Mechanical Engineering, 2015, 28(6) : 1163-1170.

[5] TRIM A D, BRAATEN H, LIE H, et al. Experimental investigation of vortex-induced vibration of long marine risers[J]. Journal of Fluids Structures, 2005, 21: 335-361.

[6] XU J, WANG D S, HUANG H, et al. A vortex-induced vibration model for the fatigue analysis of a marine drilling riser[J]. Ships and Offshore Structures, 2017, 12(S1): 280-287.

[7] 王嘉松, 蒋世全, 许亮斌. 深水钻井隔水管浴激振动特 性的数值模拟研究 [J]. 石油钻采工艺, 2015，37(1): 30-35.

WANG Jiasong, JIANG Shiquan, XU Liangbin. Numerical simulation of drilling riser vortex induced vibration characteristics in deepwater[J]. Oil Drilling \& Production Technology, 2015, 37(1): 30-35.

[8] 陈国明, 刘秀全, 畅元江, 等. 深水钻井隔水管与井口 技术研究进展 $[\mathrm{J}]$. 中国石油大学学报, 2013, 37(5): 129-139.

CHEN Guoming, LIU Xiuquan, CHANG Yuanjiang, et al. Advances in technology of deepwater drilling riser and wellhead[J]. Journal of China University of Petroleum, 2013, 37(5): 129-139.

[9] TAGGART S, TOGNARELLI M A. Offshore drilling riser VIV suppression devices: what's available to operators?[C]// American Society of Mechanical Engineers. Proceedings of the ASME 27th International Conference on Offshore Mechanics and Arctic Engineering, June 15-20, 2008, Estoril, Portugal. New York: ASME, 2008: OMAE 57047.

[10] 孙友义, 陈国明, 畅元江, 等. 基于涡激抑制的隔水管 浮力块分布方案优化 $[\mathrm{J}]$. 中国石油大学学报, 2009, 33(3): 123-127.

SUN Youyi, CHEN Guoming, CHANG Yuanjiang, et al. Riser buoyancy distribution optimization based on vortex-induced vibration suppression[J]. Journal of China University of Petroleum, 2009，33(3): 123-127.

[11] 许亮斌, 蒋世全, 畅元江, 等. 浮力块对深水钻井隔水 管主要性能的影响 [J]. 中国海上油气，2007，19(5): 338-342.

XU Liangbin, JIANG Shiquan, CHANG Yuanjiang, et al. Effect of buoyancy modules on main performances of deepwater drilling riser[J]. China Offshore Oil and Gas, 2007, 19(5): 338-342.

[12] HOLMES S, OAKLEY O H, RAGHAVAN K, et al. Using CFD to study the effects of staggered buoyancy on drilling riser VIV[C]// American Society of Mechanical Engineers. Proceedings of the ASME 27th International Conference on Offshore Mechanics and Arctic Engineering, June 15-20, 2008, Estoril, Portugal. New York: ASME, 2008: OMAE 57434

[13] LI L, FU S, YANG J, et al. Experimental investigation on vortex-induced vibration of risers with staggered buoyancy[C]// American Society of Mechanical Engineers. Proceedings of the ASME 2011 30th International 
Conference on Ocean, Offshore and Arctic Engineering, June 19-24, 2011, Rotterdam, The Netherlands. New York: ASME, 2011: OMAE 49046.

[14] FANG S M, NIEDZWECKI J M, FU S, et al. VIV response of a flexible cylinder with varied coverage by buoyancy elements and helical strakes[J]. Marine Structures, 2014, 39: 70-89.

[15] VANDIVER J K, LI L. SHEAR7 V4.3 program theoretical manual[M]. Massachusetts: Department of Ocean Engineering Massachusetts Institute of Technology, 2003.

[16] TOGNARELLI M A, YIN F, CAMPBELL M, et al. Benchmarking of SHEAR7 V4.5: comparisons to full-scale drilling riser VIV data and legacy analyses[R].
OMAE 79442, 2009

[17] 畅元江, 杨焕丽, 刘秀全, 等. 深水钻井隔水管-井口 系统涡激疲劳详细分析 [J]. 石油学报, 2014, 35(1): 146-151.

CHANG Yuanjiang, YANG Huanli, LIU Xiuquan, et al. Detailed analysis of vortex induced fatigue for deep-water drilling riser-wellhead system[J]. Acta Petrolei Sinica, 2014, 35(1): 146-151.

作者简介: 刘秀全(通信作者), 男, 1987 年出生, 博士, 副教授。主要 研究方向为深水钻井隔水管完整性技术。

E-mail:1xqmcae@163.com

陈国明, 男, 1962 年出生, 博士, 教授, 博士研究生导师。主要研究方 向为海洋油气工程及装备、油气安全工程等。

E-mail: offshore@126.com 